Volume 7

Number 2 Volume 7, No. 2, Special Issue

Summer 2014: The Global SOF Network

Article 7

\title{
Redefining the Indirect Approach, Defining Special Operations Forces (SOF) Power, and the Global Networking of SOF
}

Scott Morrison

NATO Special Operations Headquarters, Commander's Action Group, scott.morrison@nshq.nato.int

Follow this and additional works at: https://digitalcommons.usf.edu/jss

pp. $48-54$

\section{Recommended Citation}

Morrison, Scott. "Redefining the Indirect Approach, Defining Special Operations Forces (SOF) Power, and the Global Networking of SOF." Journal of Strategic Security 7, no. 2 (2014) : 48-54.

DOI: http://dx.doi.org/10.5038/1944-0472.7.2.6

Available at: https://digitalcommons.usf.edu/jss/vol7/iss2/7

This Article is brought to you for free and open access by the Open Access Journals at Digital Commons @ University of South Florida. It has been accepted for inclusion in Journal of Strategic Security by an authorized editor of Digital Commons @ University of South Florida. For more information, please contact digitalcommons@usf.edu. 


\title{
Redefining the Indirect Approach, Defining Special Operations Forces (SOF) Power, and the Global Networking of SOF
}

\author{
Abstract \\ The current Defense Strategy assigns Special Operations Forces (SOF) to play a central \\ role in countering terrorism, weapons of mass destruction, and irregular warfare. However, \\ there has been little published that defines the role of Special Operations alongside air, \\ land, and sea domains. The U.S. Special Operations Community struggles to define its own \\ theoretical concepts such as direct approach and indirect approach. The U.S. SOF circles \\ typically define direct approach with direct action and the indirect approach with foreign \\ internal defense or security force assistance. Military theorist Liddell Hart viewed the \\ indirect approach as a method to orient upon, target, and upset an adversary's equilibrium \\ in order to plan for and direct decisive blows. Today, the SOF indirect approach is arguable \\ more applicable due to the prevalence of non-state threats and internal conflicts. Following \\ Hart's definition, precision raids are among the integral components of a broader \\ application of the indirect approach. The approach also networks U.S. government power \\ as a force when used in concert with allies and local partners. Global networking along \\ with balanced precision raids will exponentially increase the utility of SOF power and \\ position it to appropriately complement all domains to tackle 21 st century challenges.
}




\section{Introduction $^{1}$}

Most military professionals and historians are familiar with the theories and concepts of air, maritime, and land power, but there has been little in the way of theory or concept as to what Special Operations power means and its strategic utility alongside those of the air, maritime, and land domains. Yet Special Operations Forces (SOF) must play a central role in several of the primary missions of the U.S. Armed Forces as projected in the Defense Strategy entitled Sustaining U.S. Global Leadership: Priorities for 21st Century Defense, such as countering terrorism, irregular warfare, and countering weapons of mass destruction. The importance of Special Operations to this new strategy was underscored in the accompanying remarks made by former Secretary of Defense Leon Panetta during the January 5, 2012 unveiling of the new defense strategy where he mentioned specifically, "as we reduce the overall defense budget, we will protect, and in some cases increase, our investments in special operations forces." Therefore, understanding the role of SOF power and how it fits within strategy is an essential prerequisite to successfully implementing the U.S. Defense Strategy.

\section{Recalibrating the Current SOF Interpretation of the Direct and Indirect Approaches}

Within the U.S. Special Operations community there has been a considerable amount of theoretical discussion, attempting to more clearly characterize the "indirect approach" as it relates to the "direct approach" in a Special Operations context. The familiar understanding in U.S. SOF circles generally associates the direct approach with direct action (DA), and the indirect approach with foreign internal defense (FID) or security force assistance (SFA). In some quarters current interpretations of these two approaches represent what is nearly a cultural schism within Special Operations due to the very different focus and skill sets associated with them. In order to understand SOF power, one first needs a recalibrated view of the direct and indirect approach frames of reference from a broader strategic vantage point.

An informative start point for exploring these topics to better define and understand the strategic utility and value of SOF power is to revert back to first principles and reconsider the roots and origins of the indirect approach. Former British soldier, historian, and military theorist Sir Basil Henry Liddell Hart is historically credited with defining the indirect approach in his work, the "Strategy of Indirect Approach,” where he asserted: “. . . throughout the ages decisive results in war have only been reached when the approach has been indirect. In strategy the longest way round is apt to be the shortest way home." ${ }^{2}$ This indirect approach of Hart focused on targeting the balance or equilibrium of an adversary noting, "while the strength of an enemy country lies outwardly in its numbers and resources, these are fundamentally dependent upon stability or equilibrium of control, morale, and supply."”

\footnotetext{
${ }^{1}$ This article was originally published in PRISM 4:3 (2014), National Defense University, Washington, D.C. It is re-printed with permission from PRISM.

${ }^{2}$ Liddell Hart, Strategy of the Indirect Approach, (London: Faber and Faber Limited, 1941), 4.

3 Ibid, 5 .
} 
The central premise of the indirect approach is to orient upon, target, and upset an adversary's equilibrium or balance to set up and enable follow-on decisive blows to be landed. Hart goes on to explain with an athletic metaphor that a direct approach without the preparatory shaping of an indirect lead is often a blunt and raw methodology that typically results in an adverse outcome; "In war as in wrestling the attempt to throw the opponent without loosening his foothold and balance can only result in self-exhaustion increasing in disproportionate ration to the effective strain put upon him. Victory by such a method can only be possible through an immense margin of superior strength in some form, and, even so, tends to lose decisiveness." " From his historical analysis of the indirect approach vice the direct approach, Hart became convinced that, "More and more clearly the fact emerged that a direct approach to one's mental object, or physical objective, along the 'line of natural expectation' for the opponent, has ever tended to, and usually produced negative results." "While the context of Hart's theory stemmed from observations of state on state conflict, the indirect approach is arguably more applicable in the complex operating environment of the 21st century where non-state threats and internal conflicts dominate the security landscape.

\section{The Indirect Approach and SOF Power}

In some circles a degree of cynicism is expressed when Special Operations are explained as small unit tactical actions performed by specially organized, trained, and equipped forces aimed at achieving strategic and operational effects. SOF alone are not a panacea or substitute, but they provide significant complementary capabilities to those of the air, land, and maritime domains. In fact, a great deal of what allows SOF to perform in a special manner are the enabling capabilities, in many cases leveraged from outside of SOF, such as:

"mobility, aerial sensors, field medics, remote logistics, engineering planners, construction, intelligence, regional specialists, interpreters/ translators, communications, dog teams, close air support specialists, security forces, and others that permit SOF operators to focus more directly on their missions."6

What SOF do however, is bring together a potent and unique mix of capabilities to the defense portfolio that enables pursuit of this indirect approach with an effect or outcome that is grossly disproportionate to the investment in resources. The SOF core activities identified by the U.S. Special Operations Command are: Direct Action, Special Reconnaissance, Unconventional Warfare, Foreign Internal Defense, Civil Affairs Operations, Counterterrorism, Psychological Operations, Information Operations, Counter-proliferation of Weapons of Mass Destruction, Security Force Assistance, Counterinsurgency Operations, and Activities Specified by the President or the Secretary of Defense (SECDEF). ${ }^{7}$ Collectively, these core activities provide a toolbox for pursuing the strategic

\footnotetext{
4 Ibid, 4.

5 Ibid, 4.

${ }^{6}$ Eric T. Olson, “U.S. Special Operations: Context and Capabilities in Irregular Warfare,” Joint

Forces Quarterly 56 (1st Qtr 2010): 68.

7 “About United States Special Operations Command Webpage," USSOCOM, available at:

http://www.socom.mil/Pages/AboutUSSOCOM.aspx.
} 
indirect approach. SOF power is the ability to apply the precise effects of these collective capabilities at carefully calibrated points of the adversary's balance or equilibrium described by Hart, whether that opponent is a state, non-state, or irregular actor in the form of an insurgent challenging an incumbent allied government. These capabilities might include the surgical application of force through offensive action, more methodical long-term efforts that support and influence others through training, advice, and assistance, or as in most instances a combination of both.

A strategy of support and influence seeks to achieve a positional advantage, exercised primarily via local indigenous forces to undermine the foundation and environment that enables the equilibrium or balance of an adversary. These local forces empowered with indigenous knowledge and information, enabled with advice and assistance, are capable of eroding an adversary's balance over time. These longer term support and influence efforts, complemented by carefully calibrated, high tempo offensive action driven by high fidelity intelligence, combine to achieve, through a strategic indirect approach, what John Arquilla and David Rondfeldt described as "swarming" to disrupt command and control, deny sanctuary, interdict lines of communication, gather information and provide strategic anticipation to inform follow-on actions and decisions. ${ }^{8}$ The tools of the current interpretation of the direct approach as it is known today, primarily offensive operations in the form of high tempo precision raids, are in fact integral components of a broader application of the strategic indirect approach. Obtaining clarity on this topic is critically important, as the value and utility of SOF power operating in this strategic indirect manner are particularly relevant to the threats and challenges faced in the 21st century security environment.

\section{Facing Nefarious Networked Actors and Today's Paradigm for Conflict}

It is no secret that the technological impact on telecommunications and modern transportation has made the world more interconnected. It has revolutionized how we look at commerce and business through a global lens of interdependence. As a result, the global international security landscape is inherently more complicated due to the same interconnected nature found in today's world of interdependent financial markets and commerce. The nature of today's threats and challenges is characterized by a complex network of nefarious state and nonstate actors ranging from insurgents and terrorists to traffickers, financial institutions, and drug cartels who collaborate wittingly and unwittingly through relationships of opportunity, convenience, dependence, shared ideology, like causes, common enemies, financial gain and brotherhood. Iran by many accounts, for example, has become extremely adept at leveraging a diverse global network of nefarious entities. The balance or equilibrium, referred to by Hart, of this loosely affiliated network is similarly complex, amorphous, and dynamic. We have seen this in over more than a decade of conflict against the network of al-Qaida.

Arquilla and Ronfeldt are not frequently credited for their concept articulated as

8 Arguilla, John and David Ronfeldt, The Advent of Netwar (Santa Monica: RAND,1996), 57. 
early as 1996, "It takes a network to fight networks." Today this phrase is unfortunately bantered about and attributed to others with little of the contextual substance and detailed understanding that made their observation so profound and prophetic. In the aftermath of September 2001 in a follow-on piece entitled "The Advent of Netwar (Revisited)," the authors brought the issue into sharper focus:

"It takes networks to fight networks. Governments that want to defend against netwar may have to adopt organizational designs and strategies like those of their adversaries. This does not mean mirroring the adversary, but rather learning to draw on the same design principles that he has already learned about the rise of network forms in the information age. These principles depend to some extent on technological innovation, but mainly on a willingness to innovate organizationally and doctrinally, perhaps especially by building new mechanisms for interagency and multijurisdictional cooperation."

This concept of requiring more dynamic configurations to enable combating networked nefarious actors bears relation to another key work by the same authors written for RAND in 1997 entitled, "A New Epoch and Spectrum of Conflict," that metaphorically describes the paradigm shift required to fight these "netwars" of the future. In this work, the traditional Western game of chess is juxtaposed as the frame of reference representing the past against the Chinese game of Go to describe the nature of the strategic paradigm shift to the future:

“Thus Go, in contrast to chess, is more about distributing one's pieces than about massing them. It is more about proactive insertion and presence than about maneuver. It is more about deciding where to stand than whether to advance or retreat. It is more about developing web-like links among nearby stationary pieces than about moving specialized pieces in combined operations. It is more about creating networks of pieces than about protecting hierarchies of pieces. It is more about fighting to create secure territories than about fighting to the death of one's pieces. Further, there is often a blurring of offense and defense-a single move may both attack and defend simultaneously. Finally, the use of massed concentrations is to be avoided, especially in the early phases of a game, as they may represent a misuse of time and later be susceptible to implosive attacks. This is quite different from chess, which is generally linear, and in which offense and defense are usually easily distinguished, and massing is a virtue. Future conflicts will likely resemble the game of Go more than the game of chess."

The work of these two authors will prove over time to be as consequential to understanding warfare in the 21st century as the thoughts of Clausewitz were to the 2oth century martial art.

\footnotetext{
9 Arquilla, John and David Ronfeldt, "The Advent of Netwar (Revisited)," in John Arquilla and David Ronfeldt (eds.), Networds and Netwars: The Future of Terror Crime, and Militancy (Santa Monica: RAND, 2001), 15.

${ }^{10}$ Arquilla, John and David Ronfeldt, “A New Epoch and Spectrum of Conflict," in John Arquilla and David Ronfeldt (eds.), In Athena's Camp, Preparing for the Conflict in the Information Age (Santa Monica: RAND, 1997), 163.
} 
The centrally important role of networks to counter nefarious networks of the 21st century has not been lost upon the United States Government after a decade plus of war against the al-Qaida network. Across innumerable U.S. national security policy documents the inexorable fact of life that the United States cannot go it alone and must work with other international actors in a comprehensive whole of government manner to achieve common security interests resonates with unmistakable clarity. Former Secretary of Defense Panetta emphasized the importance of this in a speech at the U.S. Institute of Peace in June of 2012 where he said, "In the 21st century, we must build partnerships that enable us to better meet a wider range of challenges. To that end, I see us building networks that leverage our unique capabilities-and the unique strengths of our allies and partners that share common interests-to confront the critical challenges of the future." He again reiterated this theme further in a briefing at the Pentagon in October while speaking about the ongoing implementation of the new U.S. Defense Strategy against the backdrop of fiscal challenges, "But one important way that we are going to do this is to strengthen our network of defense Alliances around the globe."

\section{The Networking of SOF Power}

With the formidable array of SOF fielded by the United States, some might question the utility and need for closer networking of U.S. SOF with allied and partner SOF around the world. As former Under Secretary of Defense for Policy Ms. Michelle Flournoy once insightfully remarked, allies and partners of the United States are more than "nice to have" or "window dressing," but are instead essential for achieving our security interests in today's world. The ultimate strategic utility of SOF power is applying a classic reinterpretation of Sir Basil Henry Liddell Hart's indirect approach to leverage SOF as a force multiplier and economy of force instrument to upset an adversary's equilibrium and balance through proactive and preventative insertion, presence, and action in coordination with a multinational collaborative network of SOF networks.

A robust and focused effort to build a global SOF network of networks supports the U.S. defense strategy in three major ways. The first is that this global networking of SOF builds relationships that engender trust and confidence among different national SOF elements enabling more effective, efficient, and coherent multinational employment and collaboration among SOF. The central importance of relationships cannot be over-emphasized; in fact this is the center of gravity relative to a multinational SOF network. This is especially important to SOF as they are in most nations a close-knit insular community stemming from their sensitive strategic and operational work that is inherently classified; often of a low visibility, clandestine, or covert nature; and quite often depends on a high degree of operational security for success and force protection. As a result, collaboration among multinational SOF depends first and foremost upon trust and confidence that underpins relationships between commanders, staffs, and SOF operators. However, without undergirding and codifying these relationships in a habitual, enduring, and substantive manner, working collaboratively alongside allies' and partners' SOF will never rise above a baseline threshold of effectiveness. What is required to build these relationships is more than transactional episodic interactions.

Transactional relationships, or those forged under the duress of hurried timelines 
are less effective, as they lack the critical foundation that leads to trust and confidence. The quality of these relationships is proportional to the value and output of the relationships. Substantive and enduring relationships that yield results require an investment of time, energy, and resources. These relationships entail understanding the culture and ethos of the different SOF elements, as well as organizational and individual capabilities, limitations, idiosyncrasies, and terminology. Concepts that engender and foster these enduring relationships among the global network of multinational SOF support the "system of defense Alliances and security partnerships" described by the Secretary of Defense as "one of America's greatest national security assets." Secretary Panetta went on to point out that "No other nation in the world really has this asset," and that "These relationships are sound investments in an era of fiscal challenges and they really do pay dividends." ${ }^{11}$ His assertion on the efficacy of these networks in response to the associated investment reaffirms the findings of seminal studies of network effectiveness by Professors Keith Provan, Brinton Milward, and Alex Turrini and others over the last decade that indicate network leadership and associated resource munificence are some of the key characteristics required to build effective networks. ${ }^{12}$

The second way this SOF network of networks is supportive of the U.S. Defense Strategy is by building allied and partner SOF national capabilities for both selfdefense and their contribution to future coalition operations. Without the appropriate capability, capacity, and interoperability, allied and partner SOF will not be postured to work effectively alongside U.S. SOF, and therefore will have diminished utility in burden sharing. Secretary of Defense Panetta highlighted the importance of this in remarks at the Pentagon stating,

"Indeed, I think it is fair to say that a vital pillar of the new defense strategy that we released this year is the important work of developing and deepening ties to other nations; developing their capabilities and building new Alliances and partnerships to build stability and security. This is one of the keys to the Defense force we are trying to build for the 21st Century."13

The third and no less critical way in which U.S. leadership of a SOF network of networks supports the U.S. Defense Strategy is by providing U.S. SOF with peacetime and contingency access. Access not only in a classic sense in terms of infrastructure such as airfields, ports and training opportunities, but more

\footnotetext{
${ }^{11}$ Secretary of Defense Leon E. Panetta and General Martin E. Dempsey (CJCS), Department of Defense News Briefing from the Pentagon, October 25, 2012, available at: http://www.defense.gov/transcripts/transcript.aspx?transcriptid $=5143$.

${ }^{12}$ Keith G. Provan and H. Brinton Milward, "Do Networks Really Work? A Framework for Evaluating Public-Sector Organized Networks," Public Administration Review 56:4 (July/August 2001): 68; Alex Turrini et al, "Networking Literature about Determinants of Network

Effectiveness," Public Administration 88:2 (2010): 540-45; Joerge Raab, "Heading Towards a Network Theory of Effectiveness: Combining Structure and Governance," Presentation at the University of Southern California Sol Price School of Public Policy Bedrosian Center, March 28, 2011, available at: http://www.youtube.com/warch?v=ksriE7B3eIM.

13 Karen Parrish, "Panetta: Defense Alliances Key to $21^{\text {st }}$ Century Security," American Forces Press Service, October 25, 2012, available at:

http://www.defense.gov/news/newsarticle.aspx?id=118346.
} 
importantly access to information, knowledge, understanding, perspective and legitimacy that are essential ingredients to operating successfully in the complex operational environment of the 21st century. As the 2008 U.S. Defense Strategy described, "Allies often possess capabilities, skills, and knowledge we cannot duplicate."14 It is for that reason that the global SOF network of networks enables a shared comprehensive understanding of today's challenges, threats, and issues that provides a broad and in depth appreciation for the nature of the problem as a point of departure for designing and implementing collaborative solutions.

\section{Conclusion}

We recognize that the nature of the nefarious networked adversary is dynamic and complex, requiring an adaptive, agile, and collaborative response. Arquilla and Ronfeldt postulated that applying the networks to fight networks paradigm would require "a willingness to innovate organizationally and doctrinally, perhaps especially by building new mechanisms for interagency and multijurisdictional cooperation." The wars in Iraq, Afghanistan, and the broader "global war on terror" stimulated more collaborative "out of the box" interagency networked collaboration to include that of a multinational nature in some cases, but there is a need to evolve and push the innovation further to enable the application of appropriate lethal and nonlethal authorities, capacities, and capabilities against adversary networks in the most effective, efficient and coherent manner. This innovative principle is well understood by the Commander of U.S. Special Operations Command, Admiral William H. McRaven, who is pursuing multiple efforts along these lines to stimulate and implement precepts originally put forward by Arquilla and Ronfeldt on how to counter the phenomenon of "netwar." The first of these initiatives is to engender and invigorate a multinational collaborative SOF network of networks around the world, and the other is to focus on and enhance a networked U.S. SOF relationship across the U.S. interagency community.

The modern version of the indirect approach is where networks of like-minded actors on today's game board of international security achieve strategic presence through proactive and preventative insertion and activity to undermine the balance and equilibrium of the adversarial networked actors. While networking as described by the Secretary of Defense is not uniquely applicable to SOF, in some cases U.S. SOF alongside allied and partner SOF, are already serving as the vanguard for precisely the type of organizational, doctrinal, and mechanistic innovation and cooperation described by Arquilla and Rondfeldt over a decade and a half ago. SOF is ideally suited to lead these innovative efforts and serve as an enabler and catalyst to engender greater multinational and inter-agency collaboration through a comprehensive approach. This global networking of SOF through a SOF network of networks will exponentially increase the utility of SOF power and position it appropriately to complement air, maritime, and land power in the 21st century.

14 U.S. Department of Defense, "National Defense Strategy 2008," (U.S. DoD: Washington, D.C., 2008), 20. 